\title{
Prevalence of Maternal Anemia in Pregnancy: The Effect of Maternal Hemoglobin Level on Pregnancy and Neonatal Outcome
}

\author{
Mohamed Abdelaziz Youssry ${ }^{1 *}$, Ahmed Mohamed Radwan², Mohamed Amin Gebreel ${ }^{3}$, \\ Tabarak Ahmed Patel ${ }^{4}$ \\ ${ }^{1}$ Obstetrics and Gynecology Department, Faculty of Medicine, Alexandria University, Alexandria, Egypt \\ ${ }^{2}$ Obstetrics and Gynecology Department, Faculty of Medicine, Zagazik University, Sharkeya, Egypt \\ ${ }^{3}$ Pediatrics Department, Faculty of Medicine, Al Azhar University, Cairo, Egypt \\ ${ }^{4}$ Clinical Pathology Department, IBN SINA College Hospital, Jeddah, Saudi Arabia \\ Email: *dr_youssry@yahoo.com
}

How to cite this paper: Youssry, M.A., Radwan, A.M., Gebreel, M.A. and Patel, T.A. (2018) Prevalence of Maternal Anemia in Pregnancy: The Effect of Maternal Hemoglobin Level on Pregnancy and Neonatal Outcome. Open Journal of Obstetrics and Gynecology, 8, 676-687.

https://doi.org/10.4236/ojog.2018.87072

Received: May 2, 2018

Accepted: June 24, 2018

Published: June 28, 2018

Copyright $(9) 2018$ by authors and Scientific Research Publishing Inc. This work is licensed under the Creative Commons Attribution International License (CC BY 4.0).

http://creativecommons.org/licenses/by/4.0/

\begin{abstract}
Objective: The aim of our study is to assess the prevalence of anemia in pregnant women, and to evaluate the effect of severity of anemia on maternal and perinatal outcome. Methods: This retrospective cohort study was conducted at the Department of Obstetrics and Gynecology from hospital records. Study population of all pregnant women who had delivered in our hospital after twenty weeks gestation between July 2014 and December 2016. Results: A total of 2654 pregnant women fulfilled the inclusion criteria, $42 \%$ were anemic, $83.3 \%$ mild anemia group (I) which represents the majority of patients and $16.7 \%$ moderate to severe anemia group (II). The majority of cases were due to iron deficiency anemia $92.8 \%$, while $7.2 \%$ were due to sickle cell trait, B-thalassemia intermedia, and other causes. The incidence of postpartum hemorrhage, cesarean delivery, and infections was significantly higher in group II compared to group I ( $5.4 \%, 40.3 \%, 3.8 \% \mathrm{Vs}, 2.9 \%, 31.0 \%, 2.0 \%$; $p$ $=0.007,0.041,0.043$ respectively). Low Apgar score, preterm labor, and low birth weight babies were significantly higher in group II compared to group I $(11.8 \%, 12.9 \%, 11.3 \%$ Vs $8.7 \%, 9.0 \%, 7.4 \% ; p=0.034,0.046,0.032)$. Conclusions: This study clarified that anemia is prevalent among pregnant women particularly mild anemia. Early diagnosis and treatment from first trimester has an essential role in managing maternal anemia and it reflects directly on the perinatal outcome. Prematurity, low birth weight infants, and postpartum hemorrhage are the commonest maternal and neonatal complications.
\end{abstract}

\section{Keywords}

Anemia, Postpartum Hemorrhage, Perinatal Outcome 


\section{Introduction}

Anemia is a condition in which red blood cells or their oxygen carrying capacity is insufficient to meet physiologic needs, which may vary according to age, sex, and pregnancy status [1]. In pregnancy, if hemoglobin level is less than $11 \mathrm{gm} / \mathrm{dl}$ in the first and third trimester, or less than $10.5 \mathrm{gm} / \mathrm{dl}$ in second trimester, the pregnant women considered anemic [2] [3]. World Health Organization reported that $18 \%$ of women from industrialized countries, and 35\% to $75 \%$ (56\% on average) of pregnant women in developing countries, are anemic [4].

Anemia is one of the most common medical disorders during pregnancy. It can cause serious adverse effects on the mother and the fetus with high risk for maternal mortality. [2]. The association of maternal anemia with pre-eclampsia and eclampsia as well as intrauterine growth restriction (IUGR), low birth weight, and increased risk of postpartum hemorrhage ( $\mathrm{PPH}$ ) [5], has been proposed [6]. Prematurity, low Apgar score and intrauterine fetal death are more common in anemic pregnant women compared to non anemic [7]. Mild anemia usually has no effect on pregnancy except that the mother may become anemic in subsequent pregnancies due to low iron stores; on the other hand severe anemia is associated with poor outcome as tachycardia, dyspnea and high cardiac output failure which may be fatal [8]. During pregnancy, iron requirements increases thus exacerbating the prevalence of anaemia, also there is a disproportionate increase in plasma volume more than red cell mass resulting in a physiological drop in hemoglobin level $(\mathrm{Hb})$ in the mid trimester [9].

Anemia in pregnancy could be due to malnutrition, blood loss, infections, chronic diseases, parasites and chronic hemolysis, and several risk factors have been recognized as unhealthy lifestyle, multiple pregnancies, alcohol, smoking, and menstrual disorders [3]. Iron and folic acid deficiency are the two most prevalent causes of anemia in pregnancy [6] [10], with subsequent fetal complications as IUGR, low birth weight, and prematurity, while vitamin B12 deficiency is rare during pregnancy as it usually causes infertility [11].

Approximately $5 \%$ of the world's populations are carriers of inherited hemoglobin disorders. Affected women with hemoglobinopathies commonly desire pregnancy when they reach childbearing age because of advances in hematological management. Successful pregnancy is possible with coordinated obstetric and medical management, and over 332,000 affected births occur annually worldwide [12]. Kobak and colleagues reported for the first time the effects of sickle cell disease on pregnancy in 1941 [13]. Pregnant women with sickle cell disease are commonly associated with complications as bacterial infection, preterm delivery, pre-eclampsia, stillbirths, and increased the risk of maternal and perinatal mortality [14] [15].

The aim of our study is to assess the prevalence of anemia in pregnant women, and evaluate the effect of severity of anemia on maternal and perinatal outcomes. Furthermore, in order to assess the relationship between maternal hemoglobin level and neonatal measures. 


\section{Patients and Methods}

This retrospective cohort study was conducted at the Department of Obstetrics and Gynecology of Ibn Sina College Hospital. It consisted of a study population of all anemic pregnant women who had delivered in our hospital between July 2014 and December 2016. Anemia was defined according to WHO classification (mild: 10 - $10.9 \mathrm{gm} / \mathrm{dl}$, moderate: 7 - $9.9 \mathrm{gm} / \mathrm{dl}$, severe: $<7 \mathrm{gm} / \mathrm{dl}$ ) [16]. This study was approved by the Hospital Research Ethics Committee and has been performed in accordance with the ethical standards as in Declaration of Helsinki (1964) and its later amendments.

\section{Sample Size Justification}

The required sample size has been calculated using the Med Calc statistical software VAT registration number is BE 0809344 640. Med Calc Software is a corporate member of the American Statistical Association. Member of the International Association of Statistical Computing.

A previous study reported that the incidence of anemia in pregnant women was approximately $40.0 \%$. From the reported data of that study, it is calculated that approximately $40.0 \%$ of women were anemic. So, it is estimated that a sample size of 2500 pregnant women from the hospital. A power of the study was $80 \%$ (type II error, 0.2 ) to detect a statistically significant difference of $3 \%$ between the anemic women using a two-sided chi-squared test with a confidence of $95 \%$ (two-sided type I error, of 0.05). This difference corresponds to a small effect size $(w)$ of 0.07 . The effect size $(w)$ is calculated as follows (Chow et al., 2003):

$$
W=\sqrt{X^{2} / N}
$$

where $\chi^{2}$ is the chi-squared statistic and $\boldsymbol{N}$ is the total sample size. The sample size was at least 2500 pregnant women.

Data collected retrospectively from anonymised hospital records; inclusion criteria include all pregnant women more than twenty weeks gestation, singleton pregnancy. Exclusion criteria include multiple pregnancies and patients who had pre-gestational systemic diseases such as, renal disease, diabetes mellitus, and hypertension. Data retrieved from files include socio-demographic profile of the mother as maternal age, anthropometric measurements [height, weight, body mass index (BMI)], smoking, women's educational and employment status. We collected data on obstetrics, and gynecology profile including gestational age (from the first day of last menstrual period), parity, medical supplementation during pregnancy, preterm labor (before completed 37 weeks), preeclampsia, mode of delivery, and post-partum hemorrhage. We also collected data on neonatal anthropometry (length, weight, and head circumference), Apgar score, and neonatal care unit admission.

\section{Statistical Analysis}

The collected data were coded, tabulated, and statistically analyzed using IBM 
SPSS statistics (Statistical Package for Social Sciences) software version 22.0, IBM Corp., Chicago, USA, 2013. Descriptive statistics were done for quantitative data as minimum \& maximum of the range as well as mean \pm SD (standard deviation) for quantitative parametric data, while it was done for qualitative data as number and percentage.

Inferential analyses for independent variables were done using Chi square test for differences between proportions and Fisher's exact test for variables with small expected numbers, while correlations were done using Pearson's correlation for numerical parametric data. T-test was used to compare between two groups if mean and S.D. was used. The level of significance was taken at $\mathrm{P}$ value $<0.050$ is highly statistically significant, otherwise is non-significant. The p-value is a statistical measure for the probability that the results observed in a study could have occurred by chance.

\section{Results}

A total of 2654 pregnant women fulfilled the inclusion criteria, $42 \%$ were anemic and they were sub-classified into mild group $83.3 \%(929 / 1115)$ that represents the majority of patients and moderate to severe group $16.7 \%(186 / 1115)$ of total anemic women. According to the etiology of anemia, the majority of cases were due to iron deficiency anemia $92.8 \%$, while $7.2 \%$ were due to sickle cell trait, B-thalassemia intermedia, and other causes. (Figure 1 and Figure 2) The socio-demographic characteristics of the study participants are illustrated in Table 1. There were no statistically significant differences between the two groups regarding BMI, educational level, smoking, and medical supplementation during pregnancy. It is observed that mild anemia was more prevalent among women below 30 years of age, while moderate to severe anemia was more prevalent above 30 years of age, and the mean maternal age was significantly higher in group II compared to group I $(28.2 \pm 4.01 \mathrm{Vs} 27.6 \pm 3.25 ; p=0.015$ respectively). The majority of anemic patients were unemployed $56.3 \%$ which was significantly higher in group II than group I, and $40.7 \%$ of anemic patients were illiterate.

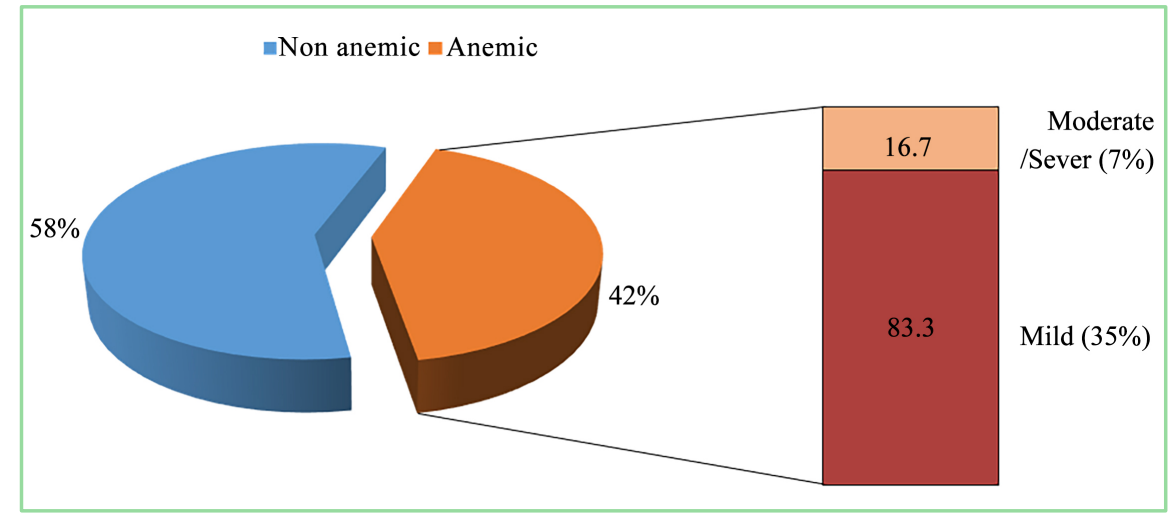

Figure 1. Incidence and severity of anemia in the studied patients. 


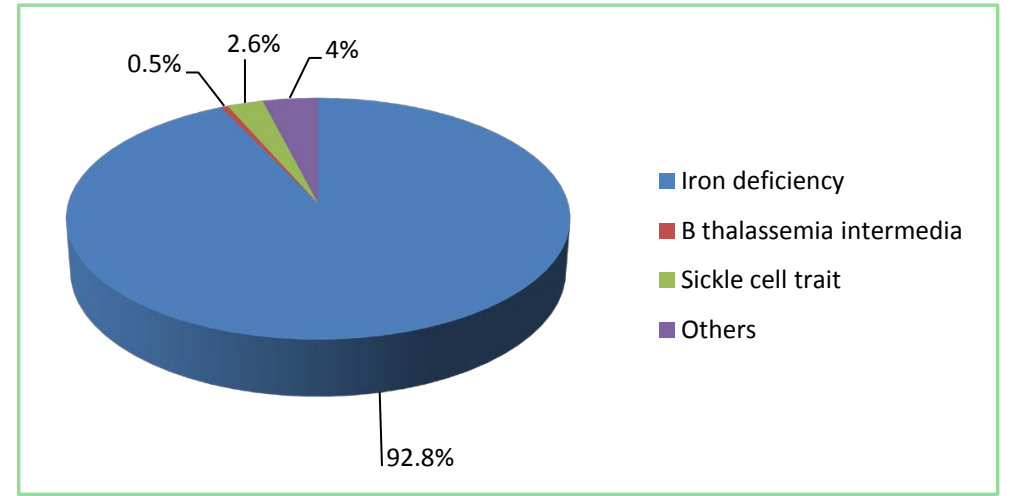

Figure 2. Causes of anemia in the studied patients.

Table 1. Socio-demographic characteristics of anemic women in both groups.

\begin{tabular}{|c|c|c|c|c|c|}
\hline \multirow[t]{2}{*}{ Parameter } & \multicolumn{2}{|c|}{$\begin{array}{l}\text { Group I } \\
\text { (mild) } \\
\text { "n=929" }\end{array}$} & \multicolumn{2}{|c|}{$\begin{array}{c}\text { Group II } \\
\text { (moderate/severe) } \\
\text { "n }=186 "\end{array}$} & \multirow[t]{2}{*}{$P$ value } \\
\hline & No. & $\%$ & No. & $\%$ & \\
\hline \multicolumn{6}{|l|}{ Maternal age } \\
\hline Below 30 & 632 & 68 & 78 & 41.9 & $0.001^{\star}$ \\
\hline Above 30 & 297 & 32 & 108 & 58.1 & \\
\hline Mean \pm SD & \multicolumn{2}{|c|}{$27.6 \pm 3.25$} & \multicolumn{2}{|c|}{$28.2 \pm 4.01$} & $0.015^{\star}$ \\
\hline \multicolumn{6}{|l|}{ BMI } \\
\hline Mean \pm SD & \multicolumn{2}{|c|}{$24.3 \pm 3.21$} & \multicolumn{2}{|c|}{$23.7 \pm 4.09$} & 0.107 \\
\hline \multicolumn{6}{|l|}{ Medical supplementation } \\
\hline Multivitamin supplementation & 223 & 24 & 35 & 18.8 & \\
\hline Iron supplementation & 288 & 31 & 38 & 20.4 & 0.113 \\
\hline None & 418 & 45 & 113 & 60.8 & \\
\hline \multicolumn{6}{|l|}{ Education } \\
\hline Post high school & 241 & 25.9 & 24 & 12.9 & \\
\hline Pre high school & 301 & 32.4 & 95 & 36.0 & 0.107 \\
\hline illiterate & 387 & 41.7 & 67 & 51.1 & \\
\hline Smoking & 102 & 11 & 26 & 14 & 0.210 \\
\hline \multicolumn{6}{|l|}{ Booking } \\
\hline Booked & 642 & 69.1 & 119 & 64.0 & 0.207 \\
\hline Unbooked & 287 & 30.9 & 67 & 36.0 & \\
\hline \multicolumn{6}{|l|}{ Employment Status } \\
\hline Employed & 427 & 46.0 & 60 & 32.3 & $0.005^{*}$ \\
\hline Housewife & 502 & 54.0 & 126 & 67.7 & \\
\hline
\end{tabular}

Data presented as numbers $(\%)$ or mean \pm SD; ${ }^{\star}$ Significant $(\mathrm{P}<0.05)$; BMI: body mass index.

As expected the mean hemoglobin level was significantly lower in group II compared to group I $(8.77 \pm 0.71$ Vs $10.2 \pm 1.8 ; p=0.001$ respectively), and anemia was more prevalent among multigravid women $60.1 \%$ which was significantly higher in group II compared to group I (66.1\% Vs 59\%; $p=0.048$ respectively). Moreover the incidence of postpartum hemorrhage, cesarean delivery, and infections was significantly higher in group II compared to group I (5.4\%, 
40.3\%, 3.8\% Vs, 2.9\%, 31.0\%, 2.0\%; $p=0.007,0.041,0.043$ respectively) (Table 2).

Regarding perinatal outcome, low Apgar score, preterm labor, and low birth weight babies were significantly higher in group II compared to group I $(11.8 \%$, $12.9 \%, 11.3 \%$ Vs $8.7 \%, 9.0 \%, 7.4 \% ; p=0.034,0.046,0.032)$. On the other hand, there were no significant differences between both groups regarding IUGR, neonatal anemia, and neonatal mortality. Table 3 When maternal hemoglobin level was correlated with other parameters, we established a significant positive correlation between maternal hemoglobin level and low birth weight $(r=0.325$, $\mathrm{p}=0.016)$, low Apgar score $(\mathrm{r}=0.333, \mathrm{p}=0.009)$, and neonatal hemoglobin level $(r=0.421, p=0.001)$, in addition to another significant positive correlation between neonatal hemoglobin level and low birth weight $(\mathrm{r}=0.32, \mathrm{p}=0.023)$.

Table 2. Obstetric characteristics of anemic women in both groups.

\begin{tabular}{|c|c|c|c|c|c|}
\hline \multirow[t]{2}{*}{ Parameter } & \multicolumn{2}{|c|}{$\begin{array}{l}\text { Group } 1 \\
\text { (mild) } \\
\text { "n=929" }\end{array}$} & \multicolumn{2}{|c|}{$\begin{array}{c}\text { Group II } \\
\text { (moderate/severe) } \\
\text { "n }=186 "\end{array}$} & \multirow[t]{2}{*}{$P$ value } \\
\hline & No. & $\%$ & No. & $\%$ & \\
\hline \multicolumn{6}{|l|}{ Hemoglobin } \\
\hline Mean \pm SD & \multicolumn{2}{|c|}{$10.2+1.8$} & \multicolumn{2}{|c|}{$8.77 \pm 0.71$} & $0.001^{*}$ \\
\hline \multicolumn{6}{|l|}{ Gestational age (weeks) } \\
\hline Mean + SD & \multicolumn{2}{|c|}{$37.9+2.50$} & \multicolumn{2}{|c|}{$37.2+3.84$} & 0.083 \\
\hline \multicolumn{6}{|l|}{ Labor } \\
\hline Pre-term labor & 84 & 9.0 & 24 & 12.9 & $0.046^{*}$ \\
\hline Term labor & 845 & 91.0 & 162 & 87.1 & \\
\hline \multicolumn{6}{|l|}{ Parity } \\
\hline Primigravida & 381 & 41.0 & 63 & 33.9 & $0.048^{*}$ \\
\hline Multigravida & 548 & 59.0 & 123 & 66.1 & \\
\hline \multicolumn{6}{|l|}{ Delivery } \\
\hline Cesarean section & 288 & 31.0 & 75 & 40.3 & $0.041^{*}$ \\
\hline Vaginal & 641 & 69.0 & 111 & 59.7 & \\
\hline Pre-eclampsia & 57 & 6.1 & 14 & 7.5 & 0.107 \\
\hline Post partum hemorrhage. & 27 & 2.9 & 10 & 5.4 & $0.007^{\star}$ \\
\hline $\begin{array}{c}\text { Infection } \\
\text { (chorioamnitis-wound } \\
\text { infection) }\end{array}$ & 19 & 2.0 & 7 & 3.8 & $0.043^{*}$ \\
\hline
\end{tabular}

Data presented as $\mathrm{n}(\%)$ or mean $\pm \mathrm{SD}$, ${ }^{\star}$ Significant $(\mathrm{P}<0.05)$.

Table 3. Maternal anemia and perinatal outcome.

\begin{tabular}{|c|c|c|c|c|c|}
\hline \multirow[t]{2}{*}{ Parameter } & \multicolumn{2}{|c|}{$\begin{array}{l}\text { Group } 1 \\
\text { (mild) } \\
\text { "n=929" }\end{array}$} & \multicolumn{2}{|c|}{$\begin{array}{c}\text { Group II } \\
\text { (moderate/severe) } \\
\text { "n=186" }\end{array}$} & \multirow[t]{2}{*}{$P$ value } \\
\hline & No. & $\%$ & No. & $\%$ & \\
\hline Prematurity & 84 & 9.0 & 24 & 12.9 & $0.046^{*}$ \\
\hline IUGR & 65 & 7.0 & 20 & 10.8 & 0.107 \\
\hline Low Apgar score (1 minute) & 81 & 8.7 & 22 & 11.8 & $0.034^{*}$ \\
\hline
\end{tabular}


Continued

\begin{tabular}{|c|c|c|c|c|c|}
\hline Mean \pm SD & \multicolumn{2}{|c|}{$6.65 \pm 2.01$} & \multicolumn{2}{|c|}{$5.21 \pm 1.72$} & $0.025^{*}$ \\
\hline $\begin{array}{l}\text { Low Birth weight } \\
\quad<2500 \mathrm{gm}\end{array}$ & 69 & 7.4 & 21 & 11.3 & $0.032^{*}$ \\
\hline Meconium stained liquor & 102 & 11.0 & 16 & 8.6 & 0.211 \\
\hline NICU admission & 98 & 10.5 & 25 & 13.4 & \\
\hline Respiratory distress & 50 & 51.0 & 15 & 60.0 & 022 \\
\hline Prematurity & 27 & 27.6 & 7 & 28.0 & \\
\hline Others & 21 & 21.4 & 3 & 12.0 & \\
\hline Neonatal mortality & 5 & 0.5 & 3 & 1.6 & 0.098 \\
\hline Neonatal anemia & 84 & 9.0 & 23 & 12.4 & 0.211 \\
\hline \multicolumn{6}{|l|}{ Birth weight } \\
\hline Mean \pm SD & \multicolumn{2}{|c|}{$2960 \pm 365.2$} & \multicolumn{2}{|c|}{$2750 \pm 422.5$} & $0.011^{\star}$ \\
\hline Length & \multicolumn{2}{|c|}{$48.0 \pm 3.92$} & \multicolumn{2}{|c|}{$46.8 \pm 4.22$} & 0.322 \\
\hline Head circumference & \multicolumn{2}{|c|}{$37.0 \pm 2.2$} & \multicolumn{2}{|c|}{$36.4 \pm 3.0$} & 0.265 \\
\hline
\end{tabular}

Data presented as numbers $(\%)$ or mean $\pm \mathrm{SD}$; ${ }^{*}$ Significant $(\mathrm{P}<0.05)$; IUGR: intrauterine growth restriction; NICU: neonatal intensive care unit.

\section{Discussion}

Anemia during pregnancy is a leading public health problem especially in poor and developing countries, it affects $30 \%-60 \%$ of pregnant women [17]. In 5\% $10 \%$ of cases anemia is severe and associated with adverse effects on pregnancy outcome [18]. The main causes of anemia involve nutrient deficiencies, infections, bleeding disorders and inherited disorders as hemoglobinopathies [19]. The prevalence of anemia depends upon socioeconomic status, parity, associated medical problems and regular antenatal care. The extent to which the maternal hemoglobin concentration affects the fetal outcome is still uncertain [20]. Two large studies published by Murphy et al. and Garn et al. included over one million pregnancies, they showed that unfavorable pregnancy outcomes are more frequent among anemic mothers [10] [21].

In our study anemia was prevalent in $42 \%$ of pregnant women, $83.3 \%$ mild anemia while $16.7 \%$ moderate to severe anemia. Many studies showed the prevalence of anemia in pregnancy with different percentages as Hussein et al. they evaluated 1721 pregnant women in Tanzania, anemia was prevalent in $68 \%$ out of which $5.8 \%$ was of moderate to severe anemia [22]. Koura et al. stated that prevalence of maternal anemia at delivery was 39.5\%, in Benin [23]. Nair et al. in another study showed that $35 \%$ of pregnant Indian women had moderate to severe anemia, while Levy et al. showed that $14 \%-62 \%$ of women in developing countries, and $16 \%-29 \%$ in developed countries are suffering from anemia [24] [25].

With consideration to the etiology of anemia among pregnant women, in the present study iron deficiency anemia was the most prevalent type $92.8 \%$, Sickle cell trait $2.6 \%$, and B-thalassemia intermedia $0.5 \%$ and anemia due to chronic hemorrhage $4 \%$ as ante-partum hemorrhage, piles, and parasitism. In the same 
context, we also observed that $60.8 \%$ in group II and $45 \%$ in group I pregnant women did not have any medical supplementation at antenatal care in the form of multivitamin or iron supplementation. Therefore, once anemia is recognized, the possibility of iron deficiency should be considered [26]. Abbaspour et al. reported that up to $50 \%$ of women even in developed countries have poor iron residual supplies, and are at risk of developing anemia if became pregnant [27]. Beck et al. in UK found that $40 \%$ of women aged 19 - 34 years had iron levels below the recommended levels [28]. We found $2.6 \%$ of anemic women sickle cell carriers while Al Qahtani et al. reported 1.1\% sickle cell disease among pregnant Saudi women, $0.5 \%$ maternal deaths, and fetal growth restriction and stillbirths accounted for $65.6 \%$ of the perinatal mortality [14].

According to the age group, we found that $68 \%$ of mild anemic pregnant women were below thirty years of age, on the other side $58.1 \%$ of moderate to severe anemic pregnant women were above thirty years of age. This is in agreement with previous studies done in UAE by Ahmed et al. they found out that anemia was more common (59.6\%) among women $\leq 30$ years of age, likewise another study done in Ethiopia by Kefiyalew et al. [29] [30].

Although, the majority of patients were booked but anemia was frequent among them $68.2 \%$, which could be attributed to different timing of booking in relation to three trimesters of pregnancy. On contrary to our results Nwizi et al. concluded that Women who booked late for antenatal care had a higher risk for anemia [31]. We evaluated the prevalence of anemia in relation to gravidity, we reported higher frequency of anemia in multigravida women $60.1 \%$ in comparison to primigravida women $39.9 \%$, this is consistent with previous study done by Zama et al. in Nigeria and they concluded that multiparity was one of the etiological factors of anemia in pregnancy [32].

The association between maternal anemia in pregnancy and adverse perinatal outcome was evaluated in the current study, our data concluded that there was increased risk of premature delivery, LBW babies, PPH. Our results showed that LBW was $8 \%$ in anemic pregnant women, and it was significantly higher in group II compared to group I in ( $11.3 \%$ Vs $7.4 \%, P=0.032$ respectively). On the other hand Hussein et al. Koura et al. and Nair et al. reported 14\% 11.3\%, 27 prevalence of LBW among anemic mothers. [22] [23] [24]. Moreover, Lone et al. concluded that low birth weight babies were 9 times more common in anemic pregnant women compared to non anemic in 626 pregnant women [7]. We also documented a significant positive correlation between maternal $\mathrm{Hb}$ and low birth weight which is in line with previous studies [33] [34]. On the other side other studies failed to find such relationship [35] [36] [37] [38].

Prematurity was present in $9.6 \%$ of our cases, which was significantly higher in group II compared to group I in $(12.9 \% \mathrm{Vs} 9 \%, P=0.046$ respectively). In agreement with our results Karaflahin et al. and Hussein et al. reported 9.9\% and $17 \%$ preterm delivery in anemic group [39] [22]. Lone et al. studied 626 pregnant women and found that preterm delivery was 4.1 times more common in anemic pregnant women compared to non anemic [7]. On the other hand, Levy 
et al. in their retrospective study, they evaluated the preterm birth and birth weights of anemic pregnant women and found no association [25]. Bondevik et al. studied 1400 pregnant women and concluded that low birth weight and preterm birth rates were significantly higher when the maternal hematocrit under 24\%. [40] Another study in India stated that severity of anemia is associated with preterm delivery as well as low birth weight with high rate of fetal mortality [41].

As regard Apgar score, we reported 9.2\% low one minute Apgar score in anemic women, and neonatal mortality was $0.7 \%$, which is consistent with Lone et al. reported that neonates of anemic women had 1.8 times increased risk having low Apgar scores at 1 minute [7]. When pregnant women were treated with iron in Niger, Apgar scores were significantly higher in those infants whose mothers received iron [42].

$\mathrm{PPH}$ is one of the most serious complications in anemic pregnant women, our data revealed 3.3\% among all anemic women (2.9\% in mild cases and $5.4 \%$ in moderate and severe cases) this is in agreement with previous studies concluded that anemia during pregnancy is associated with increased risk of PPH [5] [43]. Nair et al. in a recent study observed a 17 -fold increased risk of PPH among pregnant women with moderate-severe anemia [24]. In consideration with the mode of delivery, the incidence of cesarean delivery was $31 \%$ in group I Vs $40.3 \%$ in group II, which was significant. Likewise Karaflahin et al. found that normal delivery was $69.8 \%$ in severe anemic mothers, while Normal delivery rate of mild cases was $72.5 \%$ [39].

\section{Study Limitation}

Our study had some limitations particularly the overlapping etiological factors of anemia in some cases which was considered by accurate interpretation of data, and sometimes the course of anemia was not clarified if it was gradual or sudden which required complete data about maternal hemoglobin level throughout three trimesters of gestation. This study raises interesting issues requiring further investigations for infants born to anemic mothers for the next months for better assessment of anemia and development of infants.

\section{Conclusion}

This study clarified that anemia is prevalent among pregnant women particularly mild anemia. Early diagnosis and treatment at regular antenatal care from first trimester has an essential role in managing maternal anemia and it reflects directly on the perinatal outcome. Prematurity, low birth weight infants, and postpartum hemorrhage are the commonest maternal and neonatal complications.

\section{Declaration of Funding}

This study was not funded. 


\section{Conflict of Interest}

The authors declare that they have no conflict of interest.

\section{References}

[1] Kumar, V., Abbas, A., Fausto, N. and Aster, J. (2010) Robbins and Cotran Pathological Basis of Diseases. 8th Edition, PA Saunders/Elsevier, 640-641.

[2] UNICEF and Micronutrient Initiative (2004) Vitamin and Mineral Deficiency: A Global Progress Report, Vol. 81, 194S-1197S.

[3] Centers for Disease Control (1989) Criteria for Anemia in Children and Childbearing Aged Women. MMWR, 38, 400-404.

[4] World Health Organization (1992) The Prevalence of Anemia in Women: A Tabulation of Available Information. 2nd Edition, World health Organization, Geneva. http://www.who.int/iris/handle/10665/58994

[5] Kavle, J.A., Stoltzfus, R.J., Witter, F., Tielsch, J.M., Khalfan, S.S. and Caulfield, L.E. (2008) Association between Anemia during Pregnancy and Blood Loss at and after Delivery among Women with Vaginal Births in Pemba Island, Zanzibar, Tanzania. Journal of Health, Population and Nutrition, 26, 232-240. https://www.ncbi.nlm.nih.gov/pubmed/18686556

[6] Stephansson, O., Dickman, P.W., Johansson, A. and Cnattingius, S. (2000) Maternal Hemoglobin Concentration during Pregnancy and Risk of Stillbirth. JAMA, 284, 2611-2617. https://doi.org/10.1001/jama.284.20.2611

[7] Lone, F., Qureshi, N. and Emmanuel, F. (2004) Maternal Anaemia and Its Impact on Perinatal Outcome in a Tertiary Care Hospital in Pakistan. Eastern Mediterranean Health Journal, 10, 801-807.

[8] Sharma, B. (2003) Nutritional Anemia during Pregnancy in Non Industrial Countries. Progress in Obstetrics and Gynaecology (Studd), 15, 103-122.

[9] Rao, S. and Srikanth, S. (2013) Prevalence of Anemia in the First Trimester of Pregnancy in Rural Population of Krishna District in Andhra Pradesh India. Scholars Journal of Applied Medical Sciences, 1, 570-574.

[10] Murphy, F., O’Riordan, J., Newcombe, R., Coles, C. and Pearson, F. (1986) Relation of Hemoglobin Levels in First and Second Trimesters to Outcome of Pregnancy. Lancet, 1, 992-995. https://doi.org/10.1016/S0140-6736(86)91269-9

[11] Scott, J. and Weir, D. (1998) Role of Folic Acid/Folate in Pregnancy Prevention Is Better than Cure. Recent Advances in Obstetrics \& Gynaecology, 20, 1-20.

[12] Modell, B. and Darlison, M. (2008) Global Epidemiology of Haemoglobin Disorders and Derived Service Indicators. Bulletin of the World Health Organization, 86, 480-487. https://doi.org/10.2471/BLT.06.036673

[13] Kobak, A., Stien, P. and Daro, A. (1941) Sickle Cell Anemia in Pregnancy. A Review of the Literature and Report of Six Cases. American Journal of Obstetrics \& Gynecology, 41, 811-821. https://doi.org/10.1016/S0002-9378(41)90869-4

[14] AlQahtani, M., Alshebaily, M., AbdElzaher, M., Moawad, A. and Aljohani, N. (2012) Morbidity and Pregnancy Outcomes Associated with Sickle Cell Anemia among Saudi Women. International Journal of Gynecology \& Obstetrics, 3, 224-226. https://doi.org/10.1016/j.ijgo.2012.07.008

[15] Barfield, W., Barradas, D., Manning, S., Kotelchuck, M. and Shapiro-Mendoza, C. (2010) Sickle Cell Disease and Pregnancy Outcomes: Women of African Descent. American Journal of Preventive Medicine, 38, S542-549. 
https://doi.org/10.1016/j.amepre.2009.12.020

[16] World Health Organization (1968) Nutritional Anaemias. WHO Technical Report Series, No. 405, Report of a WHO Scientific Group, Geneva. http://whqlibdoc.who.int/trs/WHO_TRS_405.pdf

[17] McLean, E., Cogswell, M., Egli, I., Wojdyla, D. and de Benoist, B. (2009) Worldwide Prevalence of Anaemia, WHO Vitamin and Mineral Nutrition Information System, 1993-2005. Public Health Nutrition, 12, 444-454. https://doi.org/10.1017/S1368980008002401

[18] Shobeiri, F., Begum, K. and Nazari, M. (2006) A Prospective Study of Maternal Hemoglobin Status of Indian Women during Pregnancy and Pregnancy Outcome. Nutrition Research, 26, 209-213. https://doi.org/10.1016/j.nutres.2006.05.008

[19] Tolentino, K. and Friedman, J.F. (2007) An Update on Anemia in Less Developed Countries. American Journal of Tropical Medicine and Hygiene, 77, 44-51.

[20] Stoltzfus, R.J. (2001) Iron-Deficiency Anemia: Reexamining the Nature and Magnitude of the Public Health Problem. Summary: Implications for Research and Programs. The Journal of Nutrition, 131, 697S-700S.

[21] Garn, S.M., Ridella, S.A., Petzold, A.S. and Falkner, F. (1981) Maternal Hematological Level and Pregnancy Outcomes. Seminars in Perinatology, 5, 115-162.

[22] Hussein, K.L., Morgen, I., Lindmark, G., Massawe, S. and Nystrom, L. (2009) The Risks for Preterm Delivery and Low Birth Weight Are Independently Increased by the Severity of Maternal Anemia. South African Medical Journal, 99, 98-102.

[23] Koura, J.K., la Ouedraogo, S., Le Port A., Watier, L., Cottrell, G., Guerra, J., et al. (2012) Anaemia during Pregnancy: Impact on Birth Outcome and Infant Haemoglobin Level during the First 18 Months of Life. Tropical Medicine and International Health, 17, 283-291.

[24] Nair, M., Choudhury, K.M., Choudhury, S.S., Kakoty, S.D., Sarma, U.C., Webster, P., et al. (2015) Association between Maternal Anaemia and Pregnancy Outcomes: A Cohort Study in Assam, India on Behalf of the IndOSS-Assam Steering Committee. BMJ Glob Health, 1, e000026. https://doi.org/10.1136/bmjgh-2015-000026

[25] Levy, A., Fraser, D., Katz, M., Mazor, M. and Shiener, E. (2005) Maternal Anemia during Pregnancy Is a Independent Risk Factor for Low Birth Weight and Preterm Delivery. European Journal of Obstetrics \& Gynecology and Reproductive Biology, 122, 182-186. https://doi.org/10.1016/j.ejogrb.2005.02.015

[26] Shill, K.B., Karmakar, P., Kibria, G., Das, A., Rahman, M.A., Hossain, M.S., et al. (2014) Prevalence of Iron-Deficiency Anaemia among University Students in Noakhali Region, Bangladesh. Journal of Health, Population and Nutrition, 32, 103-110. https://www.ncbi.nlm.nih.gov/pubmed/24847599

[27] Abbaspour, N., Hurrell, R. and Kelishadi, R. (2014) Review on Iron and Its Importance for Human Health. Journal of Research in Medical Sciences, 19, 164-174. https://www.ncbi.nlm.nih.gov/pubmed/24778671

[28] Beck, K.L., Conlon, C.A., Kruger, R. and Coad, J. (2014) Dietary Determinants of and Possible Solutions to Iron Deficiency for Young Women Living in Industrialized Countries: A Review. Nutrients, 6, 3747-3776. https://doi.org/10.3390/nu6093747

[29] Ahmed, A., Nasir, H., Shafiq, Q., Naeem, B., Ghelani, Y. and Shaikh, R.B. (2015) The Effect of Anemia on Pregnancy and Fetal Outcome: GMC Hospital, Ajman, UAE. Gulf Medical Journal, 4, S76-S82.

[30] Kefiyalew, F., Zemene, E., Asres, Y. and Gedefaw, L. (2014) Anemia among Preg- 
nant Women in Southeast Ethiopia. Prevalence, Severity and Associated Risk Factors. BMC Research Notes, 7, 771. https://doi.org/10.1186/1756-0500-7-771

[31] Nwizi, E.N., Iliyasu, Z., Ibrahim, S.A. and Galadanci, H.S. (2011) Socio-Demographic and Maternal Factors in Anaemia in Pregnancy at Booking in Kano, Northern Nigeria. African Journal of Reproductive Health, 15, 33-41.

[32] Zama, I., Argungu, I.B., Yakubu, A., Taylor, J.R., Erhabor, O. and Suzette, U. (2014) Sociodemographic and Obstetric Factors Associated with Anemia among Pregnant Women in Sokoto, North Western Nigeria. American Association for Science and Technology, 1, 119-126.

[33] Hamalainen, H., Hakkarainen, K. and Heinonen, S. (2003) Anemia in the First But Not in the Second or Third Trimester Is a Risk Factor for Low Birth Weight. Clinical Nutrition, 22, 271-275. https://doi.org/10.1016/S0261-5614(02)00209-1

[34] Kidanto, H.L., Mogren, I., Lindmark, G., Massawe, S. and Nystrom, L. ( 2009) Risks for Preterm Delivery and Low Birth Weight Are Independently Increased by Severity of Maternal Anaemia. South African Medical Journal, 99, 98-102.

[35] Rahmati, S., Delpishe, A., Azami, M., Mohammed Reza Hafezi Ahmadi, M.R.H. and Sayehmiri, K. (2017) Maternal Anemia during Pregnancy and Infant Low Birth Weight: A Systematic Review and Meta-Analysis. International Journal of Reproductive BioMedicine, 15, 125-134. https://doi.org/10.29252/ijrm.15.3.125

[36] Monawar Hosain, M., Chatterjee, N., Begum, A. and Saha, S.C. (2005) Factors Associated with Low Birthweight in Rural Bangladesh. Journal of Tropical Pediatrics, 52, 87-91. https://doi.org/10.1093/tropej/fmi066

[37] Nasiri Amiri, F. and Ahmadi, M. (2007) Relationship between Mother Hematocrit and Pregnancy Result. Journal of Gorgan University of Medical Sciences, 9, 29-34.

[38] Morrone, A., Nosotti, L., Piombo, L., Scardella, P., Spada, R. and Pitidis, A. (2010) Iron Deficiency Anaemia Prevalence in a Population of Immigrated Women in Italy. European Journal of Public Health, 22, 256-262. https://doi.org/10.1093/eurpub/ckq144

[39] Karaflahin, E., Ceyhan, S.T., Göktolga, U., Keskin, U. and Bafler, S. (2007) Maternal Anemia and Perinatal Outcome. Perinatal Journal, 15, 127-130.

[40] Bondevik, G.T., Lie, R.T., Ulstein, M. and Kvale, G. (2001) Maternal Hematological Status and Risk of Low Birth Weight and Preterm Delivery in Nepal. Acta Obstetricia et Gynecologica Scandinavica, 80, 402-408. https://doi.org/10.1034/j.1600-0412.2001.080005402.x

[41] Kalaivani, K. (2009) Prevalence \& Consequences of Anemia in Pregnancy. Indian Journal of Medical Research, 130, 627-633.

[42] Preziosi, P., Prual, A., Galan, P., Daouda, H., Boureima, H. and Hercberg, S. (1997) Effect of Iron Supplementation on the Iron Status of Pregnant Women: Consequences for Newborns. American Journal of Clinical Nutrition, 66, 1178-1182. https://doi.org/10.1093/ajcn/66.5.1178

[43] Malhotra, M., Sharma, J.B., Batra, S., Sharma, S., Murthy, N.S. and Arora, R. (2002) Maternal and Perinatal Outcome in Varying Degrees of Anemia. International Journal of Gynecology \& Obstetrics, 79, 93-100. https://doi.org/10.1016/S0020-7292(02)00225-4 